Check for updates

Cite this: RSC Adv., 2017, 7, 20369

Received 15th January 2017

Accepted 4th April 2017

DOI: $10.1039 / c 7 r a 00629 b$

rsc.li/rsc-advances

\section{CV-APC, a colorimetric and red-emitting fluorescent dual probe for the highly sensitive detection of palladium $\uparrow$}

\author{
Jin-wu Yan, (D) Xiao-lin Wang, Lin-fu Zhou and Lei Zhang* \\ A highly sensitive colorimetric and red-emitting fluorescent dual probe was synthesized and applied to \\ imaging palladium species based on the Tsuji-Trost reaction. Notably, it displayed specific and turn-on \\ fluorescent response toward $\mathrm{Pd}^{0}$ with a vivid color change from yellow to purple in aqueous media. The \\ detection limit was calculated to be as low as $0.78 \mathrm{nM}$. Furthermore, the probe was successfully applied \\ for fluorescence imaging of palladium in living cells. All these properties made this probe a promising \\ useful tool not only in environmental detection but also more widely in bioanalytical fields.
}

\section{Introduction}

Palladium, one of the platinum-group elements, can catalyze the production of some compounds in fewer steps. ${ }^{1}$ As a result of its excellent catalytic performances, palladium has been widely used in automotive, catalytic, electrical, dental, jewelry, chemical investment and some other fields. ${ }^{2}$ However, a large amount of palladium is discharged into the environment with its excessive application. Consequently, people are exposed to palladium through inhalation and the food chain. ${ }^{3,4} \mathrm{~A}$ recent study even indicated that palladium nanoparticles could penetrate the skin and reach the dermis through skin contact. ${ }^{5}$ In contrast, people only know palladium is a potent sensitizer and may interfere with some cellular functions. ${ }^{1,6,7}$ Besides, there are limited data about the effect of palladium on environment and human health. This may partly be attributed to the lack of new methods for palladium determination. Because of traditional analytic methods such as atomic absorption spectroscopy, X-ray fluorescence, etc., which can't analyze palladium in situ and suffered from the cost of expensive instrumentation and high skilled professionals. ${ }^{8-10}$ Therefore, it is highly urgent to develop new methods for monitoring the environmental and biological level of palladium and researching on its harmful effect on human health and environment.

In this case, the fluorescent probe has attracted a lot of attention because of its simplicity and sensitivity. ${ }^{11}$ More importantly, palladium can be real-time monitored in biological samples using fluorescent probe, ${ }^{12-16}$ which enable us to trace and study the presence of palladium in the human body better.

School of Bioscience and Bioengineering, South China University of Technology, Guangzhou, P. R. China. E-mail: lzhangce@scut.edu.cn; Tel: +862039380678

$\dagger$ Electronic supplementary information (ESI) available: Synthesis and characterization of CV-APC, experimental procedures, and supplemental spectra and graphs. See DOI: 10.1039/c7ra00629b
There are some drawbacks of current palladium fluorescent probes. Firstly, some palladium probes need to be monitored in organic solvents, are not conducive to the monitoring of palladium in the environment and living cells, which reduced the practicality; secondly, most of the palladium probes are prone to response to the fluorescence but not to the UV, and which means they were difficult to be recognized by the naked eye; thirdly, the sensitivity of the reported probes need to improved, in order to realize the trace analysis of palladium. All of these drawbacks will restrict their practical usage. Therefore, it is of great value and necessity to develop new colorimetric and fluorescent dual probes for the highly sensitive and selective detection of palladium both environment and biological samples.

To overcome these drawbacks, a colorimetric and turn-on fluorescent probe, CV-APC, has been designed and synthesized. Herein, cresyl violet was chose as a signaling fluorophore because of its good solubility, excellent tissue permeability, tunable electronic system, long analytical wavelengths, high fluorescent quantum yield and efficient fluorescence quenching via the substitution of the amino group. ${ }^{17-20}$ According to the literature and our previous work, CV-APC was designed by incorporation of allyl chloroformate into cresyl violet as the response site to trap $\mathrm{Pd}^{0}$ according to the Tsuji-Trost reaction. ${ }^{21,22}$ We anticipated that the incorporation of allyl chloroformate could induce the fluorescence quenching of the cresyl violet fluorophore as a result of the decreased intramolecular charge transfer (ICT) effect, ${ }^{21}$ and the breakage of allyl chloroformate by $\mathrm{Pb}^{0}$ would result in the releasing of free cresyl violet fluorophore, accompanied with the turn-on red-emitting fluorescence and colorimetric response (Scheme 1).

\section{Results and discussion}

The desired probe CV-APC was easily prepared by attaching allyl chloroformate to cresyl violet acetate by one step reaction, and 


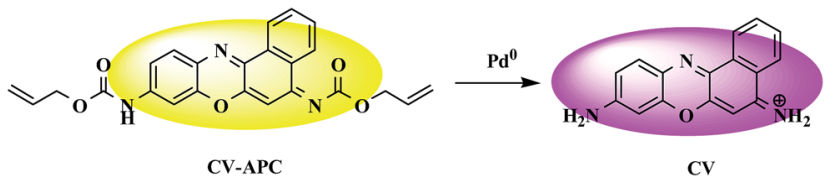

Scheme 1 Proposed sensing process of CV-APC based on the TsujiTrost reaction.

the detailed synthetic procedure is described in Scheme $\mathrm{S} 1$ in the ESI. $\dagger$ The time-dependent spectroscopic properties of probe $\mathbf{C V}$ APC $(10 \mu \mathrm{M})$ toward $\mathrm{Pd}^{0}$ were investigated in $\mathrm{CH}_{3} \mathrm{CN}-\mathrm{PBS}(1: 1, \mathrm{v} /$ v, Fig. 1) upon addition of $\operatorname{Pd}\left(\mathrm{PPh}_{3}\right)_{4}(30 \mu \mathrm{M})$. The results indicated that CV-APC displays significant absorption and emission responses to $\mathrm{Pd}^{0}$. In the absence of $\mathrm{Pd}^{0}$, there is a predominant absorbance peak around $460 \mathrm{~nm}$, after adding 3 equiv. of $\operatorname{Pd}\left(\mathrm{PPh}_{3}\right)_{4}$, the absorption peak at $460 \mathrm{~nm}$ decreased gradually and a new absorbance peak sharply appeared at around $588 \mathrm{~nm}$, which increased gradually with the incubation time and reached the maximum values after incubation for about $80 \mathrm{~min}$ at room

A

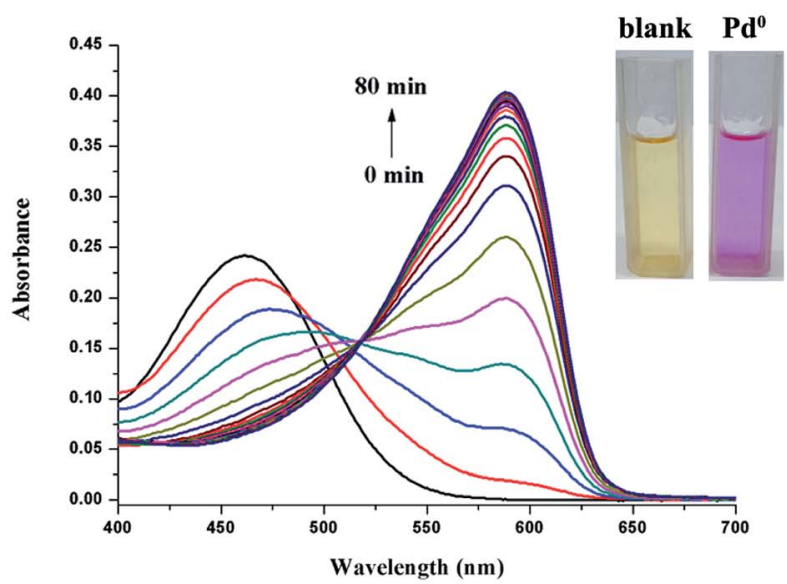

B

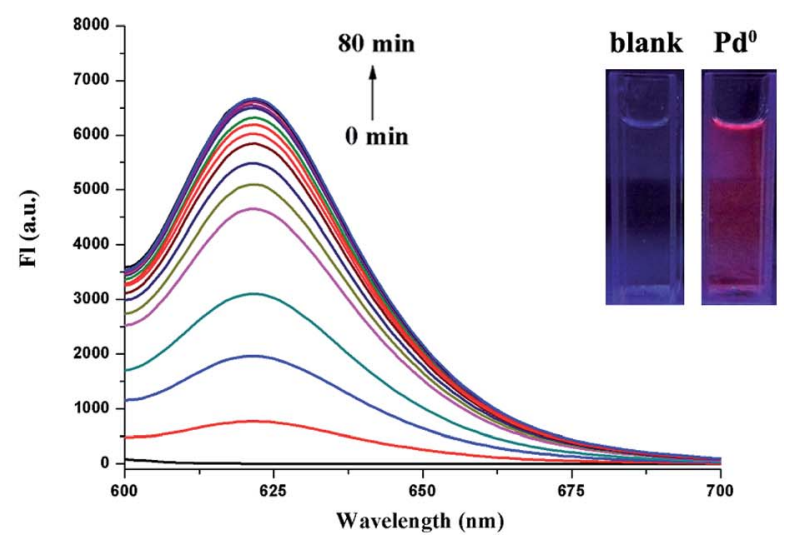

Fig. 1 UV-vis (A) and fluorescence spectral changes (B) of CV-APC against time in the presence of $\mathrm{Pd}\left(\mathrm{PPh}_{3}\right)_{4}$ (3 equiv.) in $\mathrm{CH}_{3} \mathrm{CN}-\mathrm{PBS}$ $(1: 1 \mathrm{v} / \mathrm{v})$ at room temperature. Conditions: $[\mathrm{CV}-\mathrm{APC}]=10 \mu \mathrm{M}$ and 0.5 $\mu M$, respectively; $\lambda_{\mathrm{ex}}=588 \mathrm{~nm}$. Inset: color changes and emission changes of CV-APC upon addition of $\mathrm{Pd}\left(\mathrm{PPh}_{3}\right)_{4}$. temperature (Fig. 1A). This large red shift (128 nm) of absorbance was accompanied with a vivid color change from yellow to purple (inset of Fig. 1A). Moreover, almost no emission peak was observed in the fluorescent spectrum of CV-APC alone. Upon the addition of $\mathrm{Pd}\left(\mathrm{PPh}_{3}\right)_{4}$, a dramatic enhancement of fluorescence intensity around $621 \mathrm{~nm}$ could be found and the intensity reached a plateau in $80 \mathrm{~min}$ at room temperature (Fig. 1B). The significant emission enhancement could be easily observed under the UV light (inset of Fig. 1B).

UV-vis and fluorescence titration experiments were further performed to study the sensing ability of CV-APC to $\mathrm{Pd}^{0}$. As shown in Fig. 2A, the original absorbance peak at $460 \mathrm{~nm}$ decreased and a new peak at $588 \mathrm{~nm}$ appeared with the increased concentrations of $\mathrm{Pd}\left(\mathrm{PPh}_{3}\right)_{4}$ (from 0 to $30 \mu \mathrm{M}$ ). Similarly, CV-APC had almost no fluorescence in the absence of $\mathrm{Pd}^{0}$, the emission intensity around $621 \mathrm{~nm}$ greatly enhanced with the increased concentrations of $\mathrm{Pd}\left(\mathrm{PPh}_{3}\right)_{4}$ (from 0 to 1.5 $\mu \mathrm{M}$, Fig. 1A). The turn-on fluorescence may be attributed to the releasing of free cresyl violet fluorophore through the broken of the carbamate bond, which was confirmed by the HRMS result

A

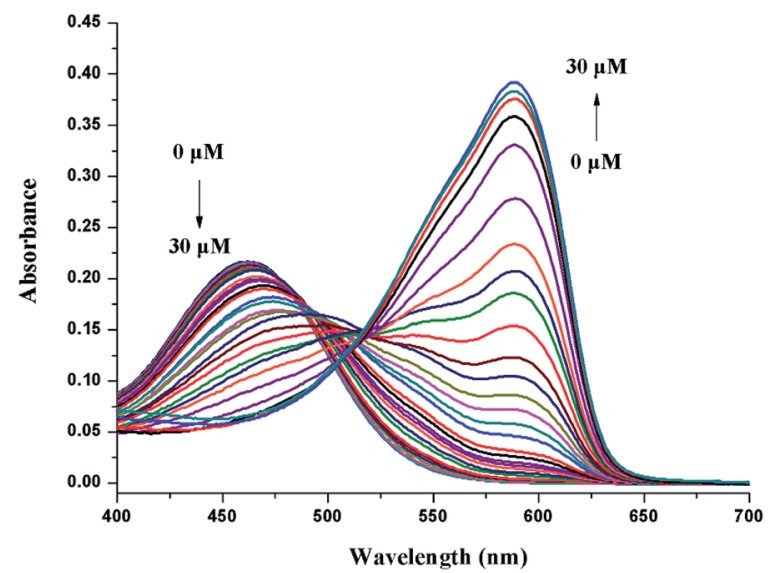

B

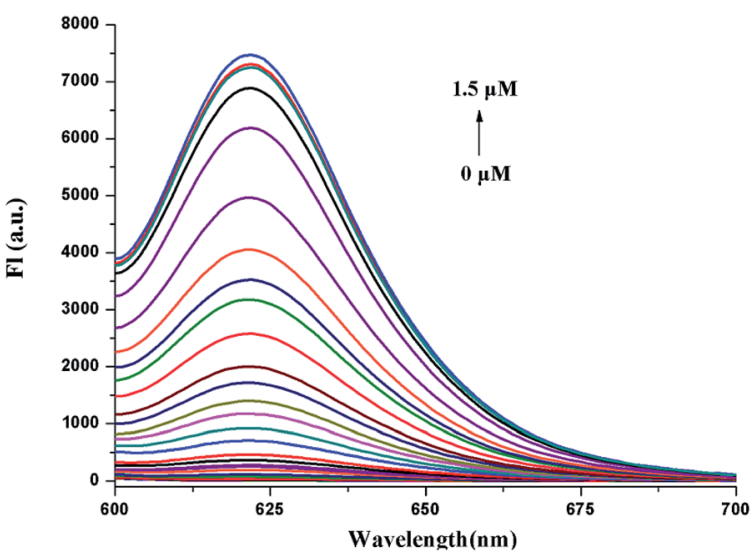

Fig. 2 UV-vis (A) and fluorescent (B) spectroscopic titration of CVAPC by stepwise addition of $\mathrm{Pd}\left(\mathrm{PPh}_{3}\right)_{4}$ in $\mathrm{CH}_{3} \mathrm{CN}-\mathrm{PBS}(1: 1 \mathrm{v} / \mathrm{v})$ at room temperature. Conditions: $[\mathrm{CV}-\mathrm{APC}]=10 \mu \mathrm{M}$ and $0.5 \mu \mathrm{M}$, respectively; $\lambda_{\mathrm{ex}}=588 \mathrm{~nm}$. The spectra were recorded at $80 \mathrm{~min}$ intervals. 
(Fig. S4 $\dagger$ ). The plots of the fluorescence intensity fit linearly with the $\mathrm{Pd}^{0}$ concentration range of $0-0.55 \mu \mathrm{M}$ with a correlation coefficient of 0.99469 (Fig. S5 $\dagger$ ). The detection limit was calculated to be as low as $0.78 \mathrm{nM}$, which shows that CV-APC is highly sensitive to $\mathrm{Pd}^{0}$, compared with reported probes for $\mathrm{Pd}^{0}$ (Table $\mathrm{S} 1 \dagger)$. According to the WHO report, residue threshold of palladium in drugs should be less than 5.0-10.0 ppm (47.0-94.0 $\mu \mathrm{M}) .^{23}$ Therefore, $\mathbf{C V}$-APC showed great potential in the trace analysis of palladium.

High selectivity is an important parameter to evaluate a newly designed fluorescent probe performance. CV-APC was treated with a wide variety of cations to assess its selectivity. As shown in Fig. 3 and $\mathrm{S} 6, \uparrow$ only the addition of $\mathrm{Pd}^{0}$ can induced significant change on the absorption and fluorescence spectra of CV-APC. In contrast, even with the treatment of 10 equivalents of other cations such as $\mathrm{Fe}^{2+}, \mathrm{Hg}^{2+}, \mathrm{Ag}^{+}, \mathrm{Ni}^{+}$, $\mathrm{K}^{+}, \mathrm{Mn}^{2+}, \mathrm{Mg}^{2+}, \mathrm{Ba}^{2+}, \mathrm{Ca}^{2+}, \mathrm{Na}^{+}, \mathrm{Cu}^{2+}, \mathrm{Ni}^{2+}, \mathrm{Co}^{2+}, \mathrm{Zn}^{2+}$ and $\mathrm{Pb}^{2+}$ (Fig. 3 and $\mathrm{S}^{\dagger}$ ), the spectra of $\mathbf{C V}$-APC had extremely weak disturbance. All these experimental results indicated that

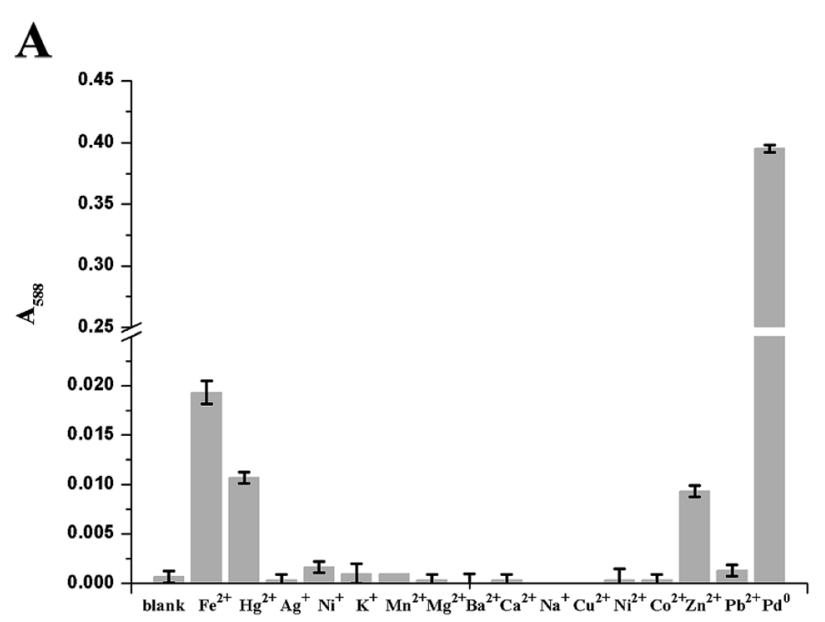

B

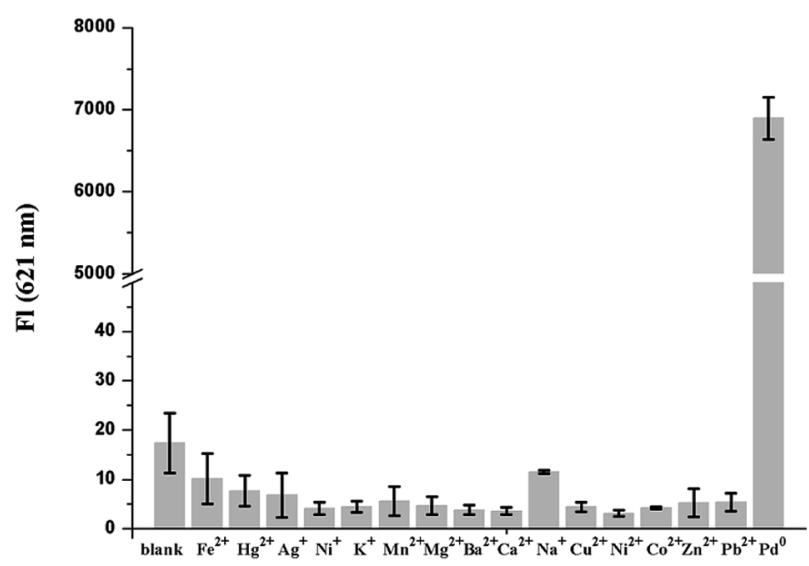

Fig. 3 Absorbance at $588 \mathrm{~nm}(\mathrm{~A})$ and fluorescence intensity at $621 \mathrm{~nm}$ (B) of CV-APC in the presence of $\mathrm{Pd}\left(\mathrm{PPh}_{3}\right)_{4}$ (3 equiv.), and the excess of representative metal ions (10 equiv.) in $\mathrm{CH}_{3} \mathrm{CN}-\mathrm{PBS}(1: 1 \mathrm{v} / \mathrm{v})$ at room temperature. Conditions: [CV-APC] $=10 \mu \mathrm{M}$ and $0.5 \mu \mathrm{M}$, respectively; $\mathrm{CH}_{3} \mathrm{CN}-\mathrm{PBS}(1: 1, \mathrm{v} / \mathrm{v}), \lambda_{\mathrm{ex}}=588 \mathrm{~nm}$. The spectra were recorded after incubation for $80 \mathrm{~min}$.

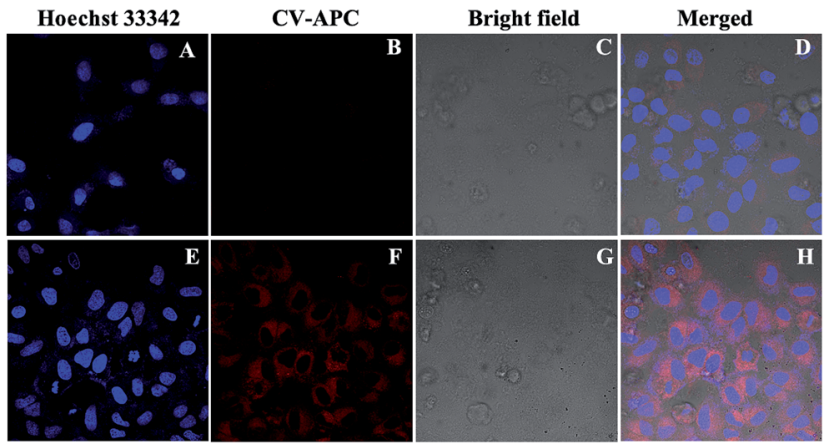

Fig. 4 Confocal fluorescence imagines of living HeLa cells. HeLa cells were co-stained with Hoechst $33342(10 \mu \mathrm{M})$ and CV-APC (10 $\mu \mathrm{M})$, without $(A-D)$ and with $(E-H)$ incubation of $\mathrm{Pd}^{0}\left(\mathrm{Pd}\left(\mathrm{PPh}_{3}\right)_{4}, 50 \mu \mathrm{M}\right)$.

CV-APC exhibited excellent selectivity for $\mathrm{Pd}^{0}$ over other metal ions.

Encouraged by the above results, fluorescent imaging pf palladium in living cells (HeLa cells) was further carried out using laser scanning confocal microscope to demonstrate the practical applicability of the probe in biological systems. In this regard, a standard MTT assay was performed to evaluate the cytotoxicity of CV-APC to HeLa cells. The results indicated that CV-APC exhibited very low cytotoxicity to living cells for $48 \mathrm{~h}$ even up to $50 \mu \mathrm{M}$ (Fig. S7 $\dagger$ ). In the study, Hoechst 33342, a commercial nuclear staining dye, was applied to co-stain cells.

As displayed in Fig. 4B, HeLa cells under normal culture condition showed almost no emission after incubation with 10 $\mu \mathrm{M}$ CV-APC. In contrast, after the addition of $50 \mu \mathrm{M} \mathrm{Pd}^{0}$, intense red fluorescence could be observed (Fig. $4 \mathrm{~F}$ and $\mathrm{H}$ ). The preliminary results indicated that $\mathbf{C V}$-APC is both cell-permeable and capable of sensing palladium in living cells, which makes CV-APC a robust and effective tool for monitoring of palladium species in both environmental samples and in living cells.

\section{Conclusions}

In summary, a highly sensitive colorimetric and red-emitting fluorescent dual probe for $\mathrm{Pd}^{0}$ has been developed based on the cresyl violet moiety through the $\mathrm{Pd}^{0}$-mediated Tsuji-Trost reaction. The proposed probe, $\mathbf{C V}-\mathbf{A P C}$, exhibits high specificity and sensitivity toward $\mathrm{Pd}^{0}$. The detection limit of the probe is $0.78 \mathrm{nM}$, which is far less than the threshold of palladium in drugs. Only $\mathrm{Pd}^{0}$ can make an obvious color change from yellow to purple, indicating that the probe can be applied in visual detection. Moreover, the live cell imaging results revealed that CV-APC holds great potential for tracking intracellular palladium species. All these properties make this probe a promising and robust tool not only in environmental monitoring but also in more widely bioanalytical fields.

\section{Acknowledgements}

This work was financially supported by the National Natural Science Foundation of China (21502056), the Natural Science Foundation of Guangdong Province, China (2016A030310463), the 
Pandeng project for undergraduate in Guangdong Province (j2twk315001-16 to L. F. Z.) and National Undergraduate Innovative and Entrepreneurial Training Program (201610561163 to L. F. Z).

\section{Notes and references}

1 C. E. Garrett and K. Prasad, Adv. Synth. Catal., 2004, 346, 889-900.

2 M. Paraskevas, F. Tsopelas and M. OchsenkühnPetropoulou, Microchim. Acta, 2012, 176, 235-242.

3 J. Kielhorn, C. Melber, D. Keller and I. Mangelsdorf, Int. J. Hyg. Environ. Health, 2002, 205, 417-432.

4 K. Ravindra, L. Bencs and R. Van Grieken, Sci. Total Environ., 2004, 318, 1-43.

5 F. Larese Filon, M. Crosera, M. Mauro, E. Baracchini, M. Bovenzi, T. Montini, P. Fornasiero and G. Adami, Environ. Pollut., 2016, 214, 497-503.

6 M. Schmid, S. Zimmermann, H. F. Krug and B. Sures, Environ. Int., 2007, 33, 385-390.

7 E. Orion, H. Matz and R. Wolf, Contact Dermatitis, 2003, 49, 216-217.

8 S. H. Fu, Z. F. Liu, S. P. Liu, J. T. Liu and A. E. Yi, Anal. Chim. Acta, 2007, 599, 271-278.

9 C. Locatelli, D. Melucci and G. Torsi, Anal. Bioanal. Chem., 2005, 382, 1567-1573.

10 B. Dimitrova, K. Benkhedda, E. Ivanova, F. Adams and J. Anal, At. Spectrosc., 2004, 19, 1394-1396.

11 Y. Yang, Q. Zhao, W. Feng and F. Li, Chem. Rev., 2012, 113, 192-270.
12 J. W. Yan, X. L. Wang, Q. F. Tan, P. F. Yao, J. H. Tan and L. Zhang, Analyst, 2016, 141, 2376-2379.

13 F. Liu, J. Du, M. Xu and G. Sun, Chem.-Asian J., 2016, 11, 4348.

14 Z. Y. Xu, X. L. Wang, J. W. Yan, J. Li, S. Guan and L. Zhang, RSC Adv., 2016, 6, 43539-43542.

15 X. Wang, Z. Guo, S. Zhu, H. Tian and W. Zhu, Chem. Commun., 2014, 50, 13525-13528.

16 M. Wang, X. Liu, H. Lu, H. Wang and Z. Qin, ACS Appl. Mater. Interfaces, 2015, 7, 1284-1289.

17 Q. Q. Wan, X. H. Gao, X. Y. He, S. M. Chen, Y. C. Song, Q. Y. Gong, X. H. Li and H. M. Ma, Chem.-Asian J., 2014, 9, 2058-2062.

18 J. Zhang, A. Shibata, M. Ito, S. Shuto, Y. Ito, B. Mannervik, H. Abe and R. Morgenstern, J. Am. Chem. Soc., 2011, 133, 14109-14119.

19 Q. Q. Wan, Y. C. Song, Z. Li, X. H. Gao and H. M. Ma, Chem. Commun., 2013, 49, 502-504.

20 J. Alijan-pour, K. Abrari, T. L. Bluki, M. T. Ghorbanian, I. Goudarzi, M. E. Salmani and M. Mirshekar, Pharmacol., Biochem. Behav., 2012, 102, 321-328.

21 F. Song, A. L. Garner and K. Koide, J. Am. Chem. Soc., 2007, 129, 12354-12355.

22 M. E. Moragues, A. Toscani, F. Sancenón, R. MartínezMáñez, A. J. P. White and J. D. E. T. Wilton-Ely, J. Am. Chem. Soc., 2014, 136, 11930-11933.

23 M. Wang, X. Liu, H. Lu, H. Wang and Z. Qin, ACS Appl. Mater. Interfaces, 2015, 7, 1284-1289. 